\title{
EXPLORING THE IMPLEMENTATION OF BIOLOGY TEACHER EDUCATION CURRICULUM THROUGH PRODUCTIVE PEDAGOGY FRAMEWORK
}

\author{
Ari Widodo \\ Biology Education Department \\ Faculty of Mathematics and Science Education, UPI \\ Bandung, Indonesia \\ Email: widodo@upi.edu
}

\author{
Rika Rafikah Agustin \\ Science Education Study Program \\ Faculty of Mathematics and Science Education, UPI \\ Bandung, Indonesia \\ E-mail: rikarafikah@upi.edu
}

\begin{abstract}
This study aims to attain an insight to curriculum implemented by Biology teacher education program at one of teacher education university in Indonesia. Nine university teachers were involved as participants as well as ten students of each course. Data were gathered from three types of courses; Biology content course, Biology pedagogy course and capita select course. Descriptive method was used with the application of student questionnaire and interview toward lecturers for gathering data as well as course syllabus document. The data was analyzed quantitatively by using descriptive statistic and qualitatively. The results reveals that the content courses cover several aspects of productive pedagogy were implemented in the curriculum. Aspect number 11 and 12 exploring higher order thinking. 4 and 5 measures deep knowledge, 13 for knowledge as problematic and 14 for knowledge integration. Connectedness to the world was identified by aspect number 15. Problem based curriculum was identified by aspects number 16. In contrast, the aspects need to be improved are 6,11 and 17 which stand for the use of text book, student's comprehension of higher order thinking and the use of project based learning. The curriculum implementation in Biology pedagogy course involve several productive pedagogy features which are higher order thinking skills, knowledge as problematic, connectedness to the world were involved during the course. On the other hand, productive pedagogies features which has not been covered are deep knowledge, knowledge integration and problem based curriculum. Whereas, the curriculum implementation in capita select course cover academic engagement, deep knowledge, deep understanding, knowledge as problematic, connectedness to real world, problem based curriculum and cooperative learning. Low productive pedagogy features occur for higher order thinking and knowledge integration.
\end{abstract}

Keywords-Productive pedagogy; Biology teacher education; The curriculum implementation

\section{INTRODUCTION}

Current science education in Indonesia is considered to have low quality. According to a study conducted by Program of International Students Assessment (PISA), Indonesia is in the $64^{\text {th }}$ rank from 65 countries [1] for science and literacy. Thus, Indonesia encountered a challenge to improve the quality with the involvement of all stakeholders in science education implementation. It is believed that one factor influencing science education quality is the teachers. Teachers are facilitators holding direct role in the implementation of science education core business which is the learning in class. Teachers know, observe, undergo as well as implement what is going on in the class room. A teacher is supposed to facilitate student to learn science effectively and achieve a number learning outcome address by curriculum.

Improving teachers' quality is a long term and sustainability process since teacher is viewed as professional educator. Teacher professional development in Indonesia acquires a great attention since 2007 when teacher certification program was established by the government and teacher professional development began to be implemented operationally in term of in-service teacher training. Previously, the attempts of teacher professional development had been conducted in Indonesia by means of a number program such as, supervision, mentoring, and, group of study. However, these programs are viewed to be insufficient to improve science education quality. Instead, pre-service teacher should be prepared to be effective teacher since they are studying in university. It was agreed that what a student in a pre-service program needs to learn is not what he/she should be, but what he/she must do in order to be effective teacher [2].

Many research focusing on how to improve pre-service science teacher competency to teach science effectively. Particularly in Biology teacher education, the focus of research mostly concern in pedagogical content knowledge (PCK) [3, 4, 5, 6], inquiry based learning [7, 8, 9, 10], and 
technology integration into pre-service Biology teacher classroom [11, 12]. However, the research investigating how the curriculum implemented for biology teacher preparation coherently is still limited. Therefore, this study attempts to explore the implementation of curriculum at Biology teacher education program comprehensively using comprehensive framework which is productive pedagogy.

On the basis of its background, the research problem of this study is how the implementation of curriculum in Biology teacher education program?

There are large number of framework used to gauge effective teaching and learning. One of them is productive pedagogy which guides teacher to reflect critically on how effective do they teach. Productive pedagogy was firstly developed by Lingard (2001) [13]. This framework is considered as a balanced framework since it concern with aspects influence the quality of teaching comprehensively including the consideration of socio-economic factor.

The productive pedagogy framework identifies four main essential characteristics of 'good' teaching which are:

- Intellectual Quality

- Connectedness

- $\quad$ Supportive Classroom environment, and

- Recognition of difference

Each of the characteristic are derived into several indicator shown by the figure 1 . The teaching that include high intellectual quality is that involves higher order thinking, deep knowledge, deep understanding, substantive conversation, knowledge as problematic and meta-language. Higher-order thinking means the transformation of information and ideas. Students undergo this transformation when they combine facts and ideas and synthesize, generalize, explain, hypothesize as well as conclude and interpret [14]. Through higher order thinking, students are encourage to solve problems, comprehend and find new meaning as they manipulate information and ideas. It is important for teachers to facilitate their students to develop their higher order thinking since it endorse student to figure out how to adapt to new situation rather than grasp new information or knowledge [15]. In contrast, lower-order thinking occurs when students are given factual information or to implement rules and algorithms through repetitive action. The instructional process is to simply deliver knowledge or practice.

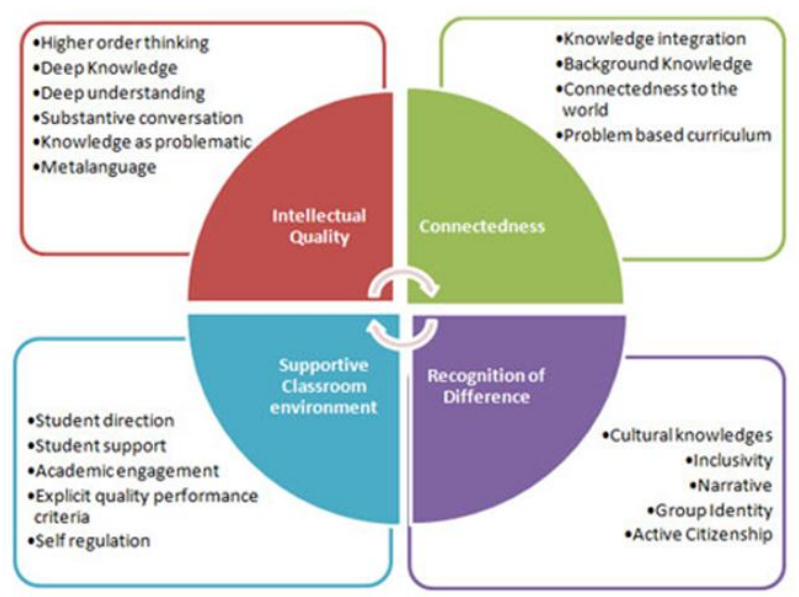

Fig. 1. Productive pedagogy framework
Students are in a similar role when they are reciting previously acquired knowledge [14].

Learning in classroom engages deep knowledge when it focused on the central ideas of a topic or discipline, which are judged to be crucial to it. Learning strategy employed by teachers essentially effect the characteristic of knowledge learned. Complex connection to the central concepts is needed to lead the concept become deep knowledge. Knowledge is considered to be superficial and when it is not connected with significant concepts or central ideas of a topic or discipline [14]. Likewise, knowledge is viewed to be shallow when it is non-problematically presented in the class. Moreover, students develop deep understanding when they catch the complex relationships between the central concepts of a topic or discipline. Unlikely, shallow understanding occurs when students retrieve only fragmented information [14]. As a result students are directed to generate new knowledge by discovering relationships, overcoming problems, constructing explanations and drawing conclusions.

Substantive conversation appears in the classroom when it involves many interactions among students, and between teacher and students. The conversation concern with the ideas of a substantive topic; the interactions are reciprocal, and promote shared understanding. Furthermore [14] identifies features of substantive conversation as shown in table 1 .

Furthermore, [14] defines characteristic of other productive pedagogy. Knowledge is considered as problematic when an understanding of knowledge being constructed and related to political, social and cultural influences and implications. It is important to present multiple contrasting and potentially conflicting forms to display knowledge as problematic. Meanwhile, meta-language is identified by incorporation of instruction on frequent discussion about: 1) talk and writing; 2) how written and spoken texts work; 3) specific technical vocabulary and words; 4) how sentences work or don't work (syntax/grammar); 5) meaning structures and text structures (semantics/genre); and 6) how discourses and ideologies work in speech and writing.

TABLE I. FEATURES OF SUBSTANTIVE CONVERSATION

\begin{tabular}{|l|l|}
\hline \multicolumn{1}{|c|}{$\begin{array}{c}\text { Features of substantive } \\
\text { conversation }\end{array}$} & \multicolumn{1}{c|}{ Characteristic } \\
\hline Intellectual substance & - Encourage critical reasoning \\
& - Moves beyond recounting \\
\hline Dialogues & - Involves sharing ideas \\
& - Students provide extended statement \\
\hline Logical extension and synthesis & - Builds on students ideas to attain \\
& collective understanding of particular \\
& topic \\
\hline A sustained exchanged & $-\begin{array}{l}\text { Exchange beyond the pattern of initiate- } \\
\text { response-evaluate }\end{array}$ \\
& $-\begin{array}{l}\text { Consists of continuous and related } \\
\text { series of linked exchange between } \\
\text { students or between teacher and } \\
\text { students }\end{array}$ \\
\hline
\end{tabular}

Supportive science classroom environment is posed by a lesson when it involves student direction, student support, academic engagement, explicit quality performance criteria, and, self-regulation. Student direction refers to students' action influencing particular activities they will do in a lesson, or how they will undertake them. In addition, students need social support which is present in the classes as the teacher supports students by expressing high expectations for them. These expectations include the following: 1) that it is necessary to take risks and try hard to master challenging 
academic work; 2) that all members of the class can learn important knowledge and skills; and 3) that a climate of mutual respect among all members of the class contributes to achievement by all. Students demonstrate academic engagement when they are thoughtful and do the assigned work. They show excitement for their work by asking questions, involved in group activities and helping peers.

The specific statement about what the student should do and reach is called explicit quality performance criteria. It should be frequent and detailed. The statement can be in form of tasks concern with performance at each stage in a lesson. Self-regulation refers to the direction of student behavior implicit and self-regulatory. In high self-regulation class, teacher rarely need to express explicit statement to drive the student being discipline.

Another feature of productive pedagogy is recognition of difference. It consists of cultural knowledge, inclusivity, narrative, group identity, and active citizenship. Cultural knowledge is knowledge about cultural identity that form cultural group. Cultural identity is represented in beliefs, languages, practices and ways of knowing. Cultural groups are distinguished by social characteristics such as gender, ethnicity, race, religion, economic status or age. Cultural diversity is valued when curriculum is constructed with the consideration of multicultural set. Inclusivity means the condition where students from different background are given opportunity to actively engage in learning. Inclusive classroom intentionally acknowledge, support and incorporate the diversity of students' diverse backgrounds, experiences and abilities. Narrative refers to the style of teaching employed by the teacher. It can be viewed as narrative or is it expository. Narrative teaching involves a connecting sequence of events. Narrative lessons emphasizes in structures and forms of both teaching as well as student response. Whereas, an expository teaching focus on written, nonfiction endorse prose, and scientific and expository expression undertaken by both teacher and students. It involves descriptions, reports, explanations, demonstrations, and the use of documentaries.

Group identity is important to support recognition of difference in classroom. It is essential to build a sense of community and identity. When difference is viewed positively, the group identity is valued. Likewise, strong sense of community is needed in classroom as well. In addition, Active citizenship is considered as one supporting elements for creating recognition of difference within classroom. It encourages the students to view that all individuals and groups have rights and responsibilities to participate in all of the democratic practices and institutions within the society.

The last feature of productive pedagogy which is connectedness involves knowledge integration, background knowledge, connectedness to the world, and problem based curriculum. Knowledge integration refers to the integration of a range of subject area into the lesson. School knowledge is recognized as integrated when explicit attempts are made to connect two or more sets of subject area knowledge, or no boundaries between subject areas are readily seen. Highconnection lessons provide students with opportunities to connect skill and competencies being learned with their own background knowledge. Connectedness stands for the degree of value and meaning a lesson has, beyond the instructional context, connection the lesson to the wider social context within which students live. Two areas in which students' work can exhibit some degree of connectedness are: 1) real-world public problems or 2) students' personal experiences. Finally, Problem-based curriculum is identified from real-world problem to solve.

\section{RESEARCH METHOD}

Descriptive methods was employed in this study to explore the implementation of curriculum in biology teacher education program with three types of course being studied to represent the figures of curriculum implementation. Those three types of course are content course, pedagogy course and capita select course. Content courses are those that study Biology content, pedagogy courses concern with teaching strategy and methodology, while capita select combine both the two other types of course. Number of courses being studied for content, pedagogy and capita select course are four, four and one respectively.

The participants were students and university teachers. Nine university teachers were involved in the study. Four of them are pedagogy course teacher, four are content teacher, and, one university teacher teach capita select which is a course combining both pedagogy and content course. Ten students of each course were involved as participant as well.

The instruments used in the study were student questionnaire, voice recorder and syllabus document of each course. Student questionnaire was used to investigate the implementation of curriculum in a course they joined. Voice recorder was used to explore information from the university teachers as well as three students of each course through interview. The documents which are course syllabi were used to triangulate data from the two other instruments.

Student questionnaire consists of 18 closed questions regarding aspects involved in the course. The students were asked to answer 'yes' or no. Voice recorder was used for interviewing three of each course as well as the university teachers. They were asked question that explore further the information that were not cover by the questionnaire. In parallel, the teachers were asked

The data of this study were analyzed quantitatively and qualitatively. Descriptive statistic was employed to analyze the data gained from student questionnaire. It was tabulated and coded. The 'yes' answer was coded as 1, while the 'no' answer was code as 0 . Furthermore, each question was presented in mean which is the total score over the number of student. Interview recording was transcribed and coded. Syllabus of courses were analyzed qualitatively as data triangulation.

\section{RESULTS AND DISCUSSION}

The framework of productive pedagogy consists of four features which are Intellectual Quality, Connectedness, Supportive Classroom environment, and Recognition of difference. Intellectual Quality can be identified when the class involves higher order thinking deep knowledge, deep understanding, substantive conversation, knowledge as problematic and meta-language. Connectedness is indicated by several aspects that are knowledge integration, background knowledge, connectedness to the world, and, and problem based curriculum. The components of supportive classroom environment are student direction, student support, academic engagement, explicit quality performance criteria, and, selfregulation. Whereas, Recognition of difference is supported by cultural knowledge, inclusivity, narrative, group identity, and, active citizenship [13]. Several aspects of the eighteen 
questions are in line with the frame work. Table 2 shows several aspects explored in the study and their appropriateness to features of productive pedagogy.

TABLE II. ASPECTS OF CURRICULUM BEING EXPLORED

\begin{tabular}{|l|l|}
\hline Question & \multicolumn{1}{|c|}{ Aspect } \\
\hline 1 & Course relevancy with future job \\
\hline 2 & Congruity of course and the lesson \\
\hline 3 & Opportunity to engage actively in the lesson \\
\hline 4 & Deep knowledge \\
\hline 5 & Deep knowledge \\
\hline 6 & The use of text book \\
\hline 7 & Classroom as learning context \\
\hline 8 & The use of test/examination \\
\hline 9 & The use of non-test assessment \\
\hline 10 & Variety of learning resources \\
\hline 11 & Comprehension of higher order thinking \\
\hline 12 & The opportunity to develop higher order thinking \\
\hline 13 & Knowledge as problematic \\
\hline 14 & Knowledge integration \\
\hline 15 & Connectedness to the world \\
\hline 16 & The use Problem based learning \\
\hline 17 & The use of project based learning \\
\hline 18 & The use of cooperative learning \\
\hline
\end{tabular}

The implementation of curriculum in each course which was measured by student questionnaire is presented in the Figure 2. It presents the profile of eighteen aspects implemented on the courses. According to Table 2, several aspects of productive pedagogy were implemented in the curriculum. For example, aspect number 11 and 12 exploring higher order thinking. 4 and 5 measures deep knowledge, 13 for knowledge as problematic and 14 for knowledge integration. Connectedness to the world was identified by aspect number 15. Problem based curriculum was identified by aspects number 16. Despite there is no explicit feature of productive pedagogy stating project-based and cooperative learning, it is believed that these two learning model support several feature of productive pedagogy. Project based learning refers to student-centered instruction in a prolong time period within which student plan, investigate and produce a product, presentation and performance answering a real-world problems [16, 17].

Based on the Fig 2, it is shown that the implementation of curriculum in Biology content courses covered high performance aspects that are 1, 2, 3, 4,5, 8, 10, 13, 14, 15.

Which stand for course relevancy for future job, congruity of course and the lesson, opportunity to engage actively in the lesson, deep knowledge, the use of test/examination, variety of learning resources, knowledge as problematic, knowledge integration, and connectedness to the world. Those aspects reach $0.98,1,0.98,0.85,0.93,1,0.83,0.88,0.95$ and 1 of score mean. Therefore, this study found that the curriculum of Biology content relevant with pedagogy framework which is considered to be balanced framework since it concern with aspects influence the quality of teaching comprehensively including the consideration of socio-economic factor [13].

In contrast the score of $6,7,9,11,12,16,17$ and 18 are still low with mean of each reach $0.48,0.70,0.70,0.55,0.78$, $0.65,0.53$ and 0.75 . The lowest score mean shown on question number 6 and 11 which are about the use of text book and higher order thinking comprehension. In contrast, most of the university teachers stated that they implement text book in each course.

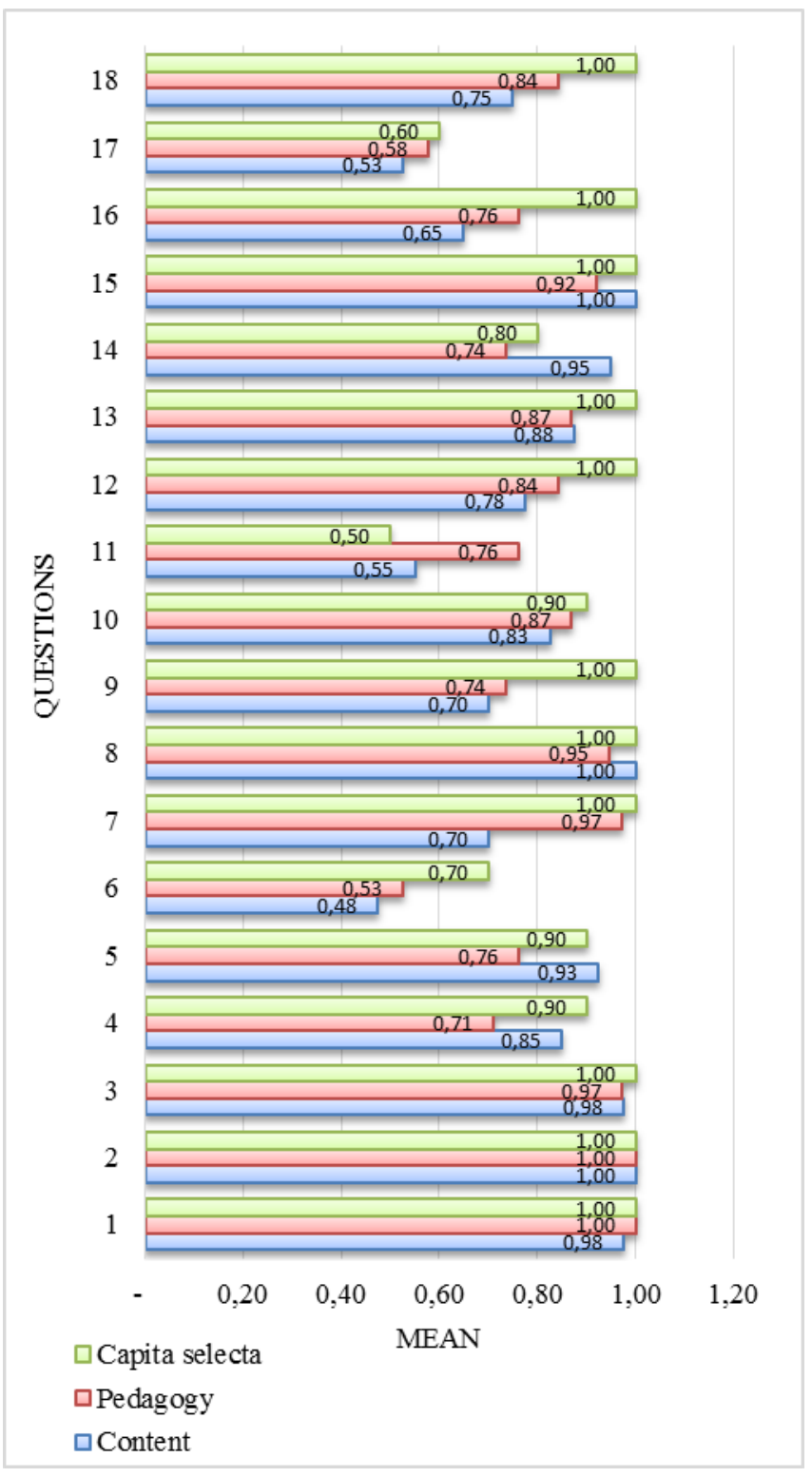

Fig. 2. Mean of implemented curriculum aspects

Detail investigation was then conducted for acquiring why there was any contrast statement between the students and university teacher. Moreover it was found that some of the university teachers use text book as learning resources but neither do the students. According to interview toward the students it is known that the teachers transform the textbook content into power point presentation and students learn mostly from it.

Students also thought that they did not comprehend higher order thinking, yet, they stated that they were allows to develop it. Further analysis shows that it is believed that this contradiction occurred because there was no explicit statement notifying them 'what is critical thinking'. However, the course activities involved these thinking skills. The students undergo transformation of information when they combine facts and ideas and synthesize, generalize, explain, hypothesize as well as conclude and interpret [14]. It is supported by the university teacher information who stated that 'the students were accustomed to hypothesize, generalize and conclude by experiment activities'. Accordingly there is different view concerning project based learning implementation. Only few students believed that there were no project based learning 
activities within the course, but the teachers said 'yes there are'.

Meanwhile, for pedagogy course it is shown that aspect number $1,2,3,7,8,10,12,13,15$ and 18 achieved high mean which is more than 0.8 . Respectively, those questions achieve yes answers of $1,1,0.97,0.95,0.87,0.84,0.87,0.92$ and 0.84 . Whereas aspect $4,5,6,9,11,14,16$ and 17 only reach 0.71 , $0.76,0.53,0.74,0.76,0.74,0.76$ and 0.58 . Thus, several productive pedagogy features covered in those pedagogy courses. Higher order thinking skills, knowledge as problematic, connectedness to the world were involved during the course. On the other hand, data shows an interesting high mean aspect, that is cooperative learning. Cooperative learning can be used to reduce unpleasant situation and increase the learning satisfaction generated from high-performance work team. It allows students to demonstrate higher academic achievement, larger perseverance, high reasoning, critical thinking skills, deeper understanding, longer time for tasks, less anxiety, greater ability to view situation from other perspective, more positive and supportive relationships with peers [18]. Therefore, the implementation of cooperative learning involves student direction, student support, academic engagement, and higher order thinking. On the other hand, productive pedagogies features which has not been covered are deep knowledge, knowledge integration and problem based curriculum. Other interesting figure is seen in question 6 and 17 which measure the use of text book and the implementation of project based learning.

In capita select course it is known that aspects achieving high mean are 1,2,3,4,5,7,8,9,10,12, 13, 14, 15,16,18 which address academic engagement, deep knowledge, deep understanding, knowledge as problematic, connectedness to real world, problem based curriculum and cooperative learning. Whereas $6^{\text {th }}, 11^{\text {th }}$, and $17^{\text {th }}$ aspect still need to be improved. With that, the data reveals that the low productive pedagogy features occur for higher order thinking and knowledge integration.

However, several productive pedagogy features were not explored since the lack of instrument and suitable data gathering technique. Another technique is needed to accomplish the study, such as, class observation. It was impossible to gather data from class observation since the time period of the study was out of courses schedule.

\section{CONCLUSION}

The implementation of curriculum to prepare Biology teacher investigated by questionnaire and interview was not exploring the productive pedagogy features completely. Nevertheless, several features were identified. That are those demonstrated in three various types of course; content, pedagogy and capita select. The data reveals that the content courses cover several aspects of productive pedagogy were implemented in the curriculum.

The curriculum implementation in Biology pedagogy course involve several productive pedagogy features which are higher order thinking skills, knowledge as problematic, connectedness to the world were involved during the course. On the other hand, productive pedagogies features which has not been covered are deep knowledge, knowledge integration and problem based curriculum. Whereas, the curriculum implementation in capita select course cover academic engagement, deep knowledge, deep understanding, knowledge as problematic, connectedness to real world, problem based curriculum and cooperative learning. Low productive pedagogy features occur for higher order thinking and knowledge integration.

\section{References}

[1] [1] Organization for Economic Development (OECD), Assessing Scientific, Reading, and Mathematical Literacy: A Framework for PISA 2012, [online], http://www.oecd.org, retrieved 15 October 2015.

[2] [2] M.Z. Ahmad., H. Jamil, N.A. Razak, "Exploring the classroom practice of productive pedagogies of the Malaysian secondary school geography teacher," Malaysia Review of International Geographical Education Online Vol. 2, No. 2, 2012.

[3] [3] E. Barnett, P.J. Friedrichsen, "Educative mentoring: how a mentor supported a pre-service biology teacher's pedagogical content knowledge development," Journal of Science Teacher Education. Vol. 26, Issue 7, pp 647-668 (3), 2015.

[4] [4] J. Großschedl, U. Harms, T. Kleickmann, I. Glowinski, "Pre service biology teachers' professional knowledge: structure and learning opportunities," Journal of Science Teacher Education, Vol. 26, Issue 3, pp 291-318 (4), 2015.

[5] [5] A.O. Santau, J.L. Maerten-River, S. Bovis, J. Orend, “A mile wide or an inch deep? improving elementary pre-service teachers' science content knowledge within the context of a science methods course," Journal of Science Teacher Education, Vol. 25, Issue 8, pp 953-976, 2015.

[6] [6] S.J. Krajewski, R. Schwartz, "A community college instructor's reflective journey toward developing pedagogical content knowledge for nature of science in a non-majors undergraduate biology course, "Journal of Science Teacher Education, Vol. 25, Issue 5, pp 543-566, 2014.

[7] [7] V. Pilitsis, R.G. Duncan, "Changes in Belief Orientations of Preservice Teachers and Their Relation to Inquiry Activities," Journal of Science Teacher Education, Vol. 23, Issue 8, pp 909-936, 2012.

[8] [8] E. Buckner, P. Kim, "Integrating technology and pedagogy for inquiry-based learning: The Stanford Mobile Inquiry-based Learning Environment (SMILE)," Journal of science teacher education, Vol. 44, Issue 1, pp 99-118, 2013.

[9] B.M. Shore, T. Chichekian, C.A. Syer, M.W. Aulls, C.H. Rederiksenle "Planning, enactment, and reflection in inquiry-based learning: validating the Mc. Gill strategic demands of inquiry questionnaire," International Journal of Science and Mathematics Education, Vol. 10, Issue 2, pp 315-337, 2012.

[10] E.J.S. Kang, J.A. Bianchini, G.J. Kelly, "Crossing the border from science student to science teacher: preservice teachers' views and experiences learning to teach inquiry. Journal of science teacher education. Vol. 24, Issue 3, pp 427-447, 2012.

[11] N. Janssen and A.W. Lazonder, "Implementing innovative technologies through lesson plans: what kind of support do teachers prefer?," J Sci. Educ Technol. DOI 10.1007/s10956-015-9573-5, 2015.

[12] N.J. Cira, A.M. Chung, A.K. Denisin, S. Rensi, G.N. Sanchez, S.R. Quake, I.H. Riedel-Kruse,"A biotic game design project for integrated life science and engineering education," PLoS Biol 13(3): e1002110 DOI: 10.1371/journal.pbio.1002110, 2013.

[13] B. Lingard, D. Hayes, M. Mills, "Teachers and Productive Pedagogies: contextualizing, conceptualizing, utilizing," Pedagogy, Culture \& Society, Vol.11, Number 3, 2003.

[14] New Basics Branch and the Queensland School Reform Longitudinal Study (QSRLS), A Guide to Productive Pedagogies Classroom reflection manual. Brisbane: Teaching and Learning Branch Education House, 2002.

[15] R.B. Williams, Higher order thinking skills. Challenging all students to achieve. Delaware: Sky horse, 2015.

[16] M. Holm, "Project-based instruction: a review of the literature on effectiveness in Prekindergarten through 12th grade classrooms," In Sight Rivier Acad. J 7(2):1-13, 2011.

[17] A. Habók, J. Nagy, “ In-service teachers' perceptions of project-based learning” Springer Plus 5:83 DOI 10.1186/s40064-016-1725-4, 2015.

[18] R.M. Felder and R. Brent, Department of Chemical Engineering, N.C. State University, Raleigh, NC 27695-7905 Education Designs, Inc., Cary, NC 27518. 